\title{
DEPTH RESOLVED STRAIN AND PHASE MAPPING OF DISSIMILAR FRICTION STIR WELDS USING HIGH ENERGY SYNCHROTRON RADIATION
}

\author{
R.V. MARTINS ${ }^{\mathrm{a}, *}$ and V. HONKIMÄKI ${ }^{\mathrm{b}}$ \\ ${ }^{a}$ Materials Research Department, Riso National Laboratory, DK-4000 Roskilde, Denmark; \\ ${ }^{\mathrm{b}}$ European Synchrotron Radiation Facility, B.P. 220, F-38043 Grenoble Cedex, France
}

(Received 26 June 2003)

\begin{abstract}
The strain and phase distribution in a dissimilar friction stir weld of AA6082-T6 to AA2024-T3 is investigated non-destructively. The measurements are performed using a novel depth resolved strain and phase mapping technique. The technique is based on the use of a focussed high energy synchrotron beam, a novel spiral slit system, and an area detector system. Through thickness measurements of the residual strain along the weld centre show strong variations with changes of sign. The strain scans across the weld exhibit a strong asymmetry in particular for the longitudinal strain component. A depth resolved strain mapping across the weld shows for the dominant longitudinal strain component variations in depth, especially on the AA6082 side of the weld. Results from the strain measurements are related to the depth resolved map of the material distribution in the weld zone.
\end{abstract}

Keywords: Friction stir weld; Spiral slit; Residual strain; High energy synchrotron radiation

\section{INTRODUCTION}

Friction stir welding (FSW) is a welding technique that was developed in the early 90s at The Welding Institute (UK) (Thomas et al., 1991). FSW is a solid state welding process in which a spinning tool is forced along the joint line, heating the abutting material from the two components. It bears a high potential for larger applications in the automotive and aerospace industries (Thomas and Nicholas, 1997). A great advantage is, in particular, the possibility of joining dissimilar materials, which are not, or only with great difficulties weldable by classic fusion welding techniques. One of the possible applications is for example the welding of high performance materials, such as particle reinforced Al alloy, to larger structures made from a lower performance, but less expensive, alloy.

*Corresponding author. 
An important issue of the suitability of a weld for a particular application is, apart of the microstructure, the residual stress state since they can have a large impact on the lifetime of the weld. Several authors have been reporting on this issue in the past (e.g. Webster et al., 2001; Sutton et al., 2002; Reynolds et al., 2003). However, in most of the cases a weld of similar materials was investigated. In general the stress component parallel to the weld line is the dominant one, being tensile with around $150 \mathrm{MPa}$ in the weld region. These are balanced by compressive stresses further away from the weld. The stresses in transverse direction are generally slightly tensile.

In the past most investigations of FSW of dissimilar materials focussed on the microstructural properties (e.g. Murr et al., 2000). The present investigation aims to determine the residual stress field in a FSW of a specific dissimilar material combination (AA6082-T6 to AA2024-T3) and to relate these results to observations about the material distribution in the weld zone.

\section{SAMPLE}

The investigated dissimilar weld was made from AA2024 in T3 condition and AA6082 in T6 condition. Both alloys are age hardenable. AA2024-T3 has poor fusion weldability and is commonly used to build structures for aerospace applications. AA6082-T6 is a typical extrusion alloy. Its yield strength at room temperature is near $260 \mathrm{MPa}$, about $75 \%$ of the yield strength of AA2024-T3 $(\sim 345 \mathrm{MPa})$. At a temperature of $371^{\circ} \mathrm{C}$ the yield strength of AA6082-T6 is about $12 \mathrm{MPa}$, less than $50 \%$ of the yield strength of AA2024-T3 (28 MPa) (Metals Handbook 1990, due to unavailability the value for AA6082-T6 at $371^{\circ} \mathrm{C}$ was taken from AA6061-T6, which has a similar thermal stability and strength due to the similar $\mathrm{Mg}, \mathrm{Si}$ and $\mathrm{Cu}$ content). The panel and weld dimensions are given in Fig. 1. The grains of the AA2024 base material are pancake shaped, lying in plane with the panel, with a diameter of $\sim 200 \mu \mathrm{m}$ and a thickness of about $30 \mu \mathrm{m}$. The smoothness of the X-ray diffraction patterns recorded for the strain and phase analysis indicates that the AA6082 base material has a coarser grain structure.

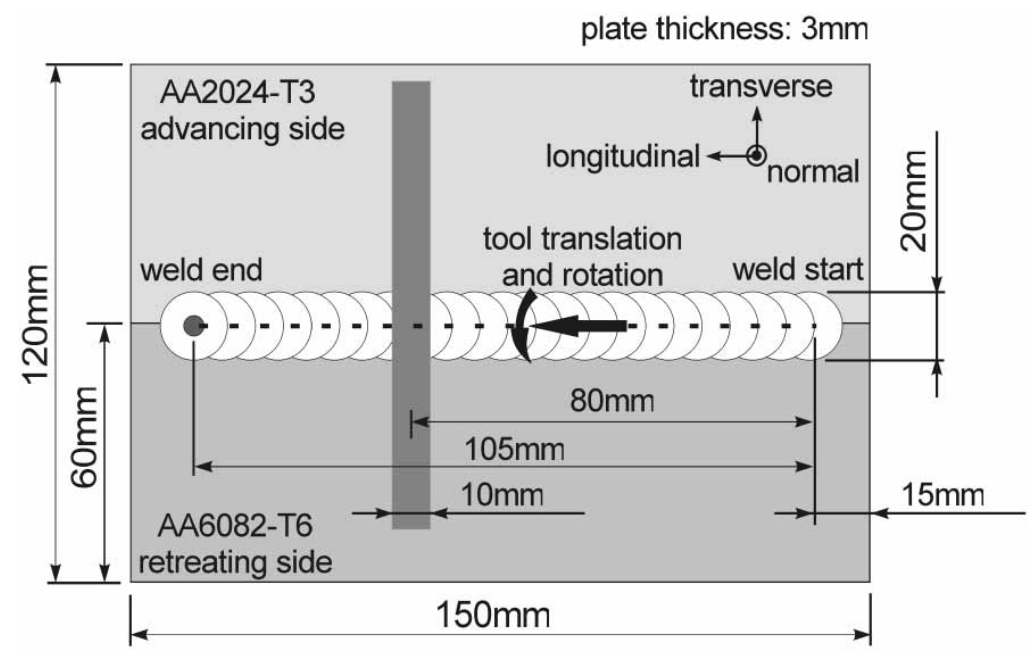

FIGURE 1 Schematic of the weld, sample coordinate system and measurement locations. 
The welding tool had an M6 threaded pin and a shoulder diameter of $20 \mathrm{~mm}$. The pin tip was plunged $2.8 \mathrm{~mm}$ deep into the $3 \mathrm{~mm}$ thick plates. The rotation and weld speed of the tool were $600 \mathrm{rev} / \mathrm{min}$ and $200 \mathrm{~mm} / \mathrm{min}$ respectively.

\section{EXPERIMENTAL TECHNIQUE}

For the non-destructive and depth resolved strain and phase mapping of the weld a novel technique was applied. The technique was developed at the European Synchrotron Radiation Facility. The experimental setup is shown in Fig. 2. The sample is placed on translation and rotation units for the alignment. A high energy X-ray beam with an energy of $88 \mathrm{keV}(\lambda=0.1409 \AA)$ with a $40 \mu \mathrm{m}$ wide and $10 \mu \mathrm{m}$ high focal spot at the sample position was penetrating the sample. The depth resolution was achieved with a spiral slit system (Honkimäki et al., 2003). The slit system consists of 12 equidistant concentric spiral appertures cut into a W plate. All paths through the $2 \mathrm{~mm}$ thick $\mathrm{W}$ plate lie on cones, which have one common apex (i.e. the focal point of the slit system; here $50 \mathrm{~mm}$ ). The slit system was placed $50 \mathrm{~mm}$ behind the focal spot of the X-ray beam. It accepts all Bragg reflections emerging from the sample within the angular range of $2 \theta=5$ to $35^{\circ}$. The slit gap, adjustable from 0 to $100 \mu \mathrm{m}$, was set to $25 \mu \mathrm{m}$. Due to the depth acceptance parallel to the X-ray beam a spinning capillary (not shown in the figure), containing standard reference Si powder and Al powder, could be placed before the sample providing the reference information for each recorded diffraction pattern. The patterns were monitored with a large area detector system, in the present case a MAR345 online image plate scanner. Each recorded image contains the depth resolved information for a two-dimensional strain distribution and the material composition. In order to determine a triaxial stress state an additional image was recorded at each position with the sample rotated by $60^{\circ}$ around the $\omega$ axis. This obviously degrades the spatial resolution parallel to the weld. However, the effect is rather small taking into consideration the plate thickness

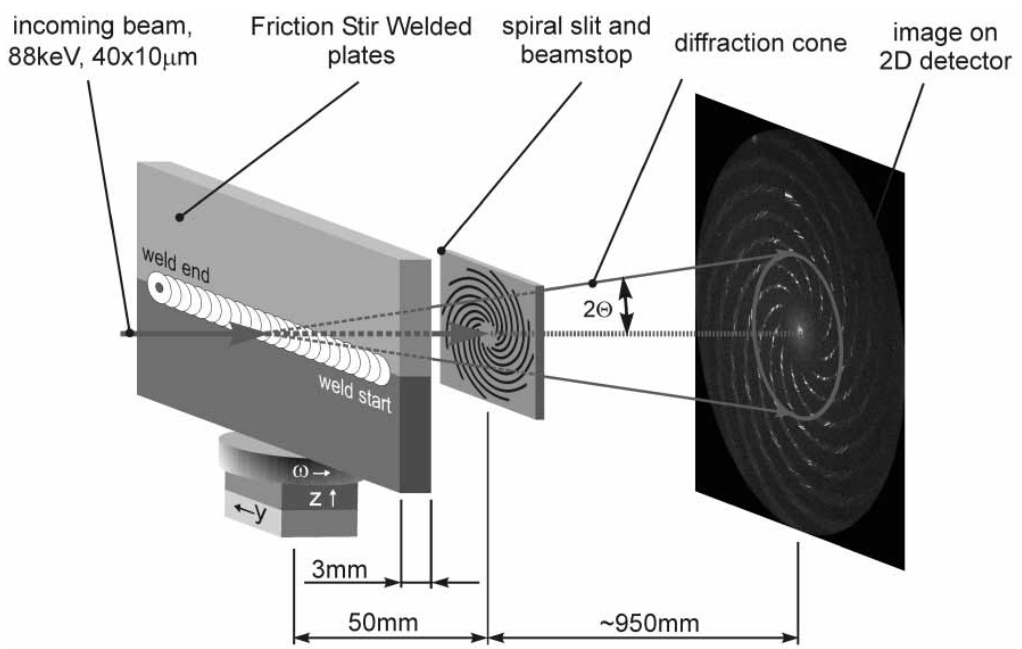

FIGURE 2 Scheme of the experimental setup with spiral slit and two-dimentional detector. 
of $3 \mathrm{~mm}$ and the fact that the gradients parallel to the weld are not very steep in the region investigated. The strain distribution was measured along two lines. One line crossed the weld at $80 \mathrm{~mm}$ from the weld start (see Fig. 1). The step size along this line was of $1 \mathrm{~mm}$ in the weld region and of $4 \mathrm{~mm}$ for the outer regions. In order to improve the grain averaging the sample was oscillated during the data collection over a range of $10 \mathrm{~mm}$ parallel to the weld. The second scan ran along the weld centre with a step size of $15 \mathrm{~mm}$. In this case the sample was oscillated in transverse direction over a range of $5 \mathrm{~mm}$.

After applying coordinate transformations and a data reconstruction technique (Lienert et al., 2000), the residual macrostrain tensor components were determined by fitting the stress induced distortion of the recorded fractioned Debye-Scherrer rings. In a first step this was done by integration over the plate thickness and assuming that the normal stress component is zero. This results in through thickness information about the in plane residual stress state and provides information on the local value of the unstrained lattice parameter $d_{0}$. Knowing the local $d_{0}$ value the depth resolved strain distribution can be obtained under the assumption that the lattice parameter stays constant over the thickness. In fact, the maximum variation in the $d_{0}$ distribution across the weld was about $0.002 \AA$. Therefore, the latter assumption on the local $d_{0}$ was considered to be sufficiently fulfilled. The depth resolved phase distribution was derived from the differences in the recorded diffraction patterns of the two materials.

\section{RESULTS AND DISCUSSION}

In Figs. 3 and 4 the residual strain and stress distributions along the weld line centre are shown. A steep gradient is observable at the start of the weld where all components change sign within the first $15 \mathrm{~mm}$. At about $30 \mathrm{~mm}$ the longitudinal and normal strain components reach a rather constant level of about $1500 \times 10^{-6}$ and $-600 \times 10^{-6}$ respectively. In the same region the transverse strain component shows a slight decrease. Despite the relatively short total length of the weld this region could be considered as a steady state region of the welding process. At about $60 \mathrm{~mm}$ from the weld start a slight decrease of the longitudinal and normal strain component

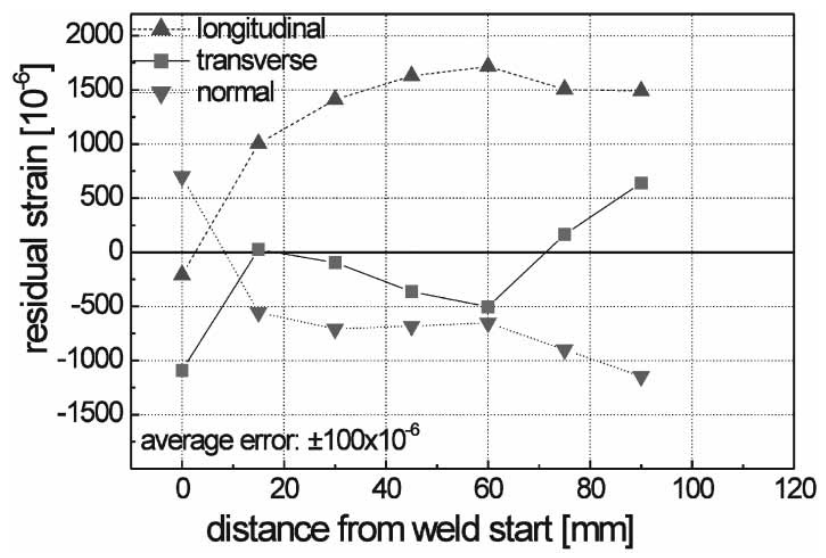

FIGURE 3 Through thickness residual strain components measured along the weld centre. 


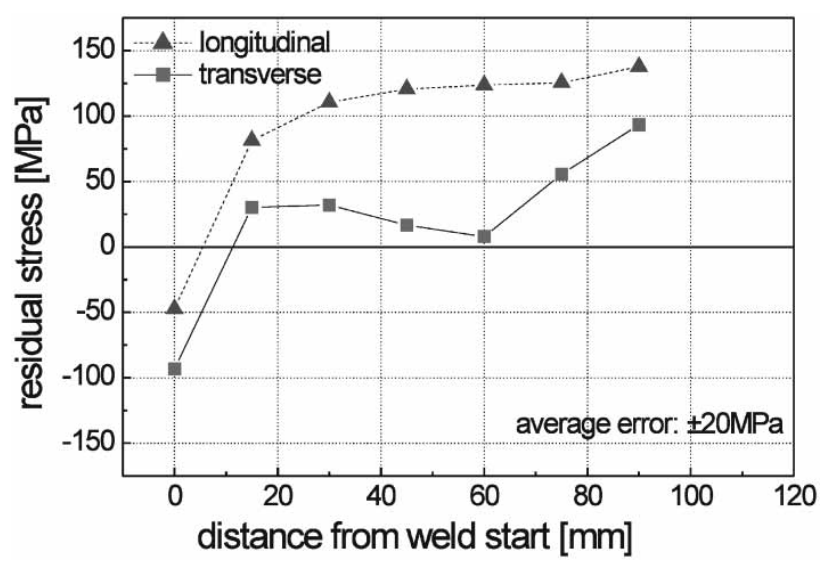

FIGURE 4 Calculated through thickness residual stress components along the weld centre.

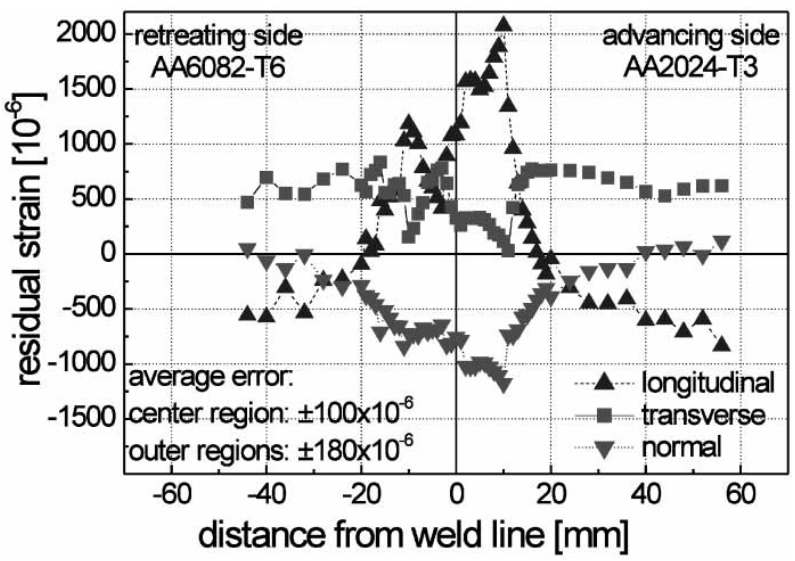

FIGURE 5 Through thickness residual strain components measured at line crossing the weld at $80 \mathrm{~mm}$ from the welds tart.

is observed while the transverse component exposes a steep increase to tensile strains of about $600 \times 10^{-6}$ close to the weld end. These observations correspond qualitatively well with modelling results published by Shi et al. (2003) for a weld made from AA2024-T3 with identical weld dimensions but slightly different welding parameters. According to them the high transverse residual stress at the weld end is possibly due to the fact that the weld finished quite far (about $30 \mathrm{~mm}$ ) from the end of the panel, causing the panel to cool faster and being more constrained. In contrast to that the inverse situation at the weld start might be explained by the fact that the weld started only $15 \mathrm{~mm}$ away from start of the panel and that, consequently, the thermal field can basically only extend ahead of the tool.

Figures 5 and 6 show the residual strain and stress profiles respectively across the weld at $80 \mathrm{~mm}$ from the weld start. The asymmetry of the residual stress and strain distributions is particularly pronounced for the longitudinal component. For this component a peak stress up to $170 \mathrm{MPa}$ is observed at the shoulder edge of the 


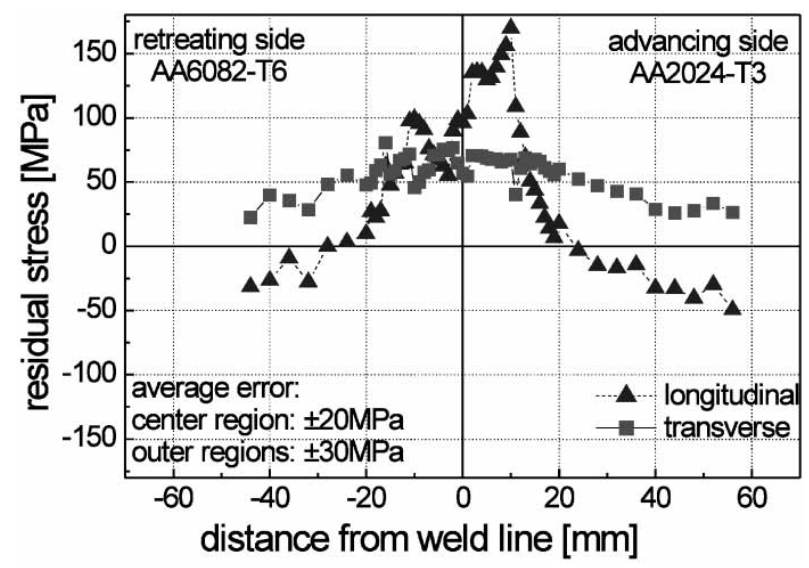

FIGURE 6 Calculated through thickness residual stress components along line crossing the weld at $80 \mathrm{~mm}$ from the weld start.

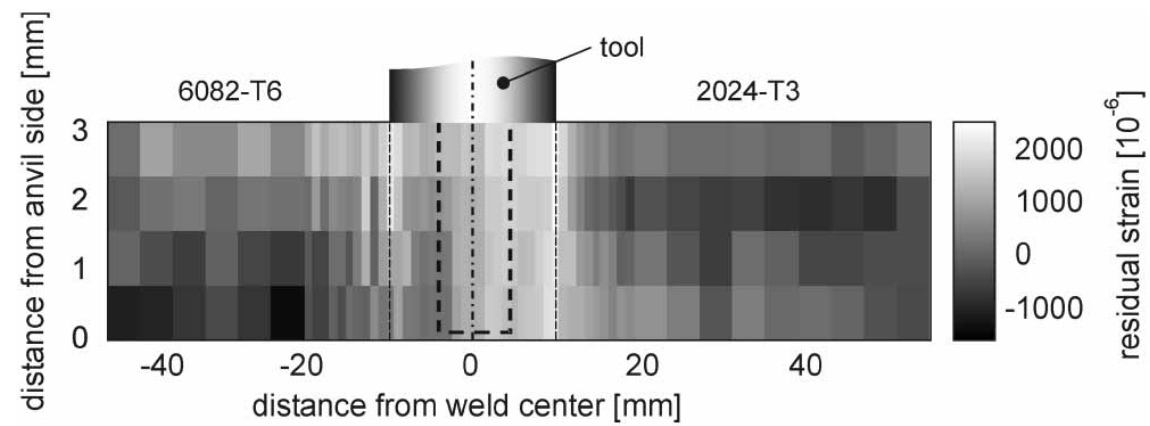

FIGURE 7 Depth resolved residual strain map of the longitudinal component along line crossing the weld $80 \mathrm{~mm}$ from the weld start.

advancing side, i.e. on the AA2024 side. This value corresponds to $\sim 50 \%$ of the yield strength of the AA2024-T3 base material. The corresponding location on the AA6082 side (i.e. at $-10 \mathrm{~mm}$ ) shows a longitudinal peak stress of about $100 \mathrm{MPa}$ which is $\sim 40 \%$ of the yield strength of the AA6082-T6 base material. The longitudinal residual stress distribution shows a local minimum of about $50 \mathrm{MPa}$ at $3 \mathrm{~mm}$ from the weld centre, which corresponds to the radius of the tool pin. The large tensile longitudinal stresses are balanced by compressive stresses far from the weld centre. The change of sign occurs on both sides at about $24 \mathrm{~mm}$ from the weld centre. The errors for the measured strains increase slightly due to the coarser microstructure outside the welding zone. The transverse stress component is with around $70 \mathrm{MPa}$ slightly higher in the centre than far away from the weld, where it decays to about $30 \mathrm{MPa}$.

In Fig. 7 the depth resolved distribution of the longitudinal residual strain component is shown. The depth distribution is rather homogeneous away from the weld. In the weld zone the strongest variations in depth are observed at $-10 \mathrm{~mm}$ (i.e. on the AA 6082 side) from the weld centre. The longitudinal strain decreases here from almost $2000 \times 10^{-6}$ on the tool side to values of around $500 \times 10^{-6}$ on the anvil side. In the corresponding position at $+10 \mathrm{~mm}$ (i.e. advancing side, AA2024), the maximum 


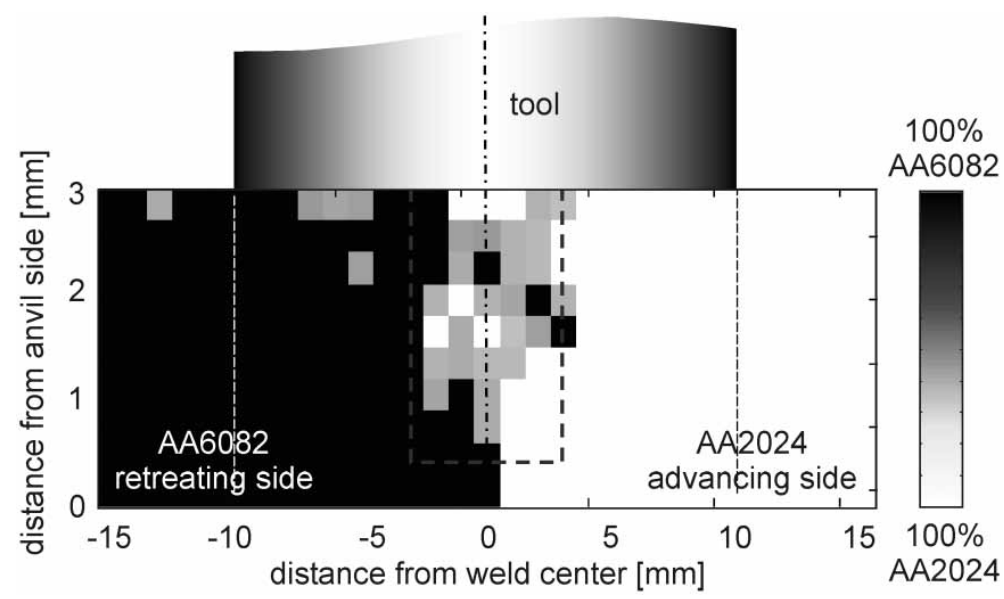

FIGURE 8 Depth resolved material distribution in the weld zone, along line crossing the weld $80 \mathrm{~mm}$ from the weld start.

strain values on the tool side are as well around $2000 \times 10^{-6}$, but the decrease towards the anvil side is much weaker. In contrast to findings by Sutton et al. (2002) and Webster et al. (2001) only very little variations with depth were observed for the normal and transverse components. This is probably mainly due to the fact that their welds were with 7 and $6 \mathrm{~mm}$ respectively, at least twice as thick as the weld investigated here. Sutton et al. (2002) also suggest that an asymmetry of the longitudinal strain profile across the weld might be caused by the higher relative velocity between tool and panel on the advancing side. However, this effect is believed to be of minor influence, especially with the given welding parameters and the similar heat conductivity of both materials. The above-mentioned modelling efforts by Shi et al. (2003) indicate that the welding tool load superposed with the thermal load creates a asymmetric strain distribution, however, for a weld of similar materials with the maximum on the retreating side. In the present case the strong asymmetry at the tool shoulder positions is believed to be mainly caused by the differences of the material properties of AA2024 and AA6083.

The local minimum in the longitudinal stress profile could be interpreted in correlation with the map of the material distribution within the weld zone, obtained from the same experimental data and shown in Fig. 8. It can be seen (within the resolution of the technique) that the zone where the local stress minimum occurs contains only material from the softer AA6082. Furthermore the map shows that the macrointerface extends mainly over the pin width, equally to both sides, with a rather good mixing (i.e. better weld quality) of both materials, for this weld where the harder material was on the advancing side. Findings by Murr et al. (2000) and Wert (2003) are pointing in the same direction in terms of the stirring direction for dissmilar welds.

\section{SUMMARY}

A novel strain and phase mapping technique was used to investigate a dissimilar friction stir weld. The sample was made from AA2024-T3 on the advancing side and AA6082-T6 
on the retreating side. Steep gradients are observed in scans along the weld centre at the beginning and the end of the welds. These may be mostly due to the differences in heat flow. A strong asymmetry of the residual strain profile across the weld is observed for the longitudinal direction. This is mainly attributed to the differences in the mechanical properties of the two materials. Only the longitudinal strain component shows strong variations in depth, in particular in the softer material (AA6082). The local minimum in the longitudinal strain profile is correlated with the depth resolved material distribution in the weld zone. It coincides with a region where, within the resolution of the technique, only the softer material is present.

\section{Acknowledgements}

This work has been supported by the European Community in the framework of the project: Joining Dissimilar Materials and Composites by Friction Stir Welding (Join-DMC). The authors wish to thank the project partners, in particular for providing the samples. The authors acknowledge the support from ESRF staff.

\section{References}

Honkimäki, V. et al. (2003). A novel non-destructive and depth-resolved strain and phase mapping technique using a spiral slit (In preparation).

Lienert, U., Martins, R., Grigull, S., Pinkerton, M., Poulsen, H.F. and Kvick, A. (2000). High spatial resolution strain measurements within bulk materials by slit-imaging. Mat. Res. Soc. Symp. Proc., 590, 241-246.

Metals Handbook, Vol. 2, pp. 70, (1990). American Society for Metals, ASM International, Metals Park, Ohio (USA).

Murr, L.E., Li, Y., Trillo, E.A. and McClure, J.C. (2000). Fundamental issues and industrial applications of friction-stir welding. Mat Tech \& Adv. Perf. Mat., 15(1), 37-48.

Reynolds, A.P., Wei Tang, Gnaupel-Herold, T. and Prask, H. (2003). Structure, properties, and residual stress of 304L stainless steel friction stir welds. Scripta Materialia, 48, 1289-1294.

Shi, Q., Dickerson, T. and Shercliff, H.R. (2003). Thermo-Mechanical FE Modelling of Friction Stir Welding of AL-2024 Including Tool Loads, Proc. 4th Int. Symp. on Friction Stir Welding, 14-16 May 2003. Park City, Utah, USA.

Sutton, M.A., Reynolds, A.P. Wang, D.-Q. and Hubbard, C.R. (2002). A Study of residual stresses and microstructure in 2024-T3 aluminum friction stir butt welds. J. of Engineering Materials and Technology, 124, 215-221.

Thomas, W.M., Nicholas, E.D., Needham, J.C., Murch, M.G., Temple-Smith, P. and Dawes, C.J. (1991). Friction Stir Butt Welding. International Patent No. PCT/GB92/02203, GB Patent No. 9125978.8 (1991), US Patent No. 5,460,317 (1995).

Thomas, W.M. and Nicholas, E.D. (1997). Friction stir welding for the transportation industries. Materials \& Design, 18(4/6), 269-273.

Webster, P.J., Djapic Oosterkamp, L., Hughes, D.J., Withers, P.J. and Vaughan, G.B.M. (2001). Synchrotron $\mathrm{X}$-ray residual strain scanning of a friction stir weld. J. of Strain Analysis, 36(1), 61-70

Wert, J.A. (2003). Microstructures of friction stir weld joints between an aluminium-base metal matrix composite and a monolithic aluminium alloy. Scripta Mater., 49(6), 607-612. 